This item was submitted to Loughborough's Research Repository by the author.

Items in Figshare are protected by copyright, with all rights reserved, unless otherwise indicated.

\title{
Rethinking design: from the methodology of innovation to the object of design
}

PLEASE CITE THE PUBLISHED VERSION

https://doi.org/10.1162/desi_a_00587

\section{PUBLISHER}

Massachusetts Institute of Technology Press (MIT Press)

VERSION

AM (Accepted Manuscript)

\section{PUBLISHER STATEMENT}

NEUBAUER, R., BOHEMIA, E. and HARMAN, K., 2020. Rethinking design: from the methodology of innovation to the object of design. Design Issues, 36 (2), pp.18-27. ( ) Massachusetts Institute of Technology. The journal homepage is at: https://www.mitpressjournals.org/loi/desi

\section{LICENCE}

CC BY-NC-ND 4.0

\section{REPOSITORY RECORD}

Neubauer, Ruth, Erik Bohemia, and Kerry Harman. 2020. "Rethinking Design: From the Methodology of Innovation to the Object of Design”. Loughborough University. https://hdl.handle.net/2134/37327. 


\section{Rethinking Design: From the Methodology of Innovation to the Object of Design Ruth Neubauer, Erik Bohemia, Kerry Harman}

\section{Making the Case for Design as a Human-Centered Methodology of Innovation}

According to proponents of user-centered design, the quest for innovating through technology has gone horribly wrong. There are concerns about the illusion of progress hiding the reality of monstrously unusable technology. This concern is expressed by Alan Cooper when he says: "The high-tech industry is in denial of a simple fact that every person with a cell phone or a word processor can clearly see: Our computerized tools are too hard to use." ${ }^{\prime 1}$ This quote directs attention to challenges of software production whereby technology often fails people and their needs. More recently, during the 2018 British Human Computer Interaction conference, a keynote presentation on artificial intelligence (AI) featured spacecraft computer HAL 9000 from the film 2001-a Stanley Kubrick film made in 1968. In the film, HAL interacts through voice with the crew, and future technology is imagined to have human-like intelligence. The video clip shown at the conference was a satire that reimagined HAL as Amazon.com's Alexa. ${ }^{2}$ Alexa is a virtual assistant and smart speaker that came to market in 2017 and reflects the current state of AI technology. In a comical twist, the computer (as Alexa) does not respond meaningfully to the crew's commands, but reacts in clearly misconceived ways to what was requested. For example, it plays the music band "The Doors" instead of opening the doors of the spacecraft as requested, or instead of answering what the problem was, it finds information about a film called "Problem Child." What we see is a computer unable to understand human speech and meaning, and the result is comical because we are familiar with technology behaving in bewildering ways. The comments from the audience suggested

Alan Cooper, The Inmates Are Running the Asylum: Why High-Tech Products Drive Us Crazy and How to Restore the Sanity (Indianapolis, IN: Sams, 2004), 14.

2 "If HAL-9000 Was Amazon.com's Alexa," YouTube, Peter Pihl, https://www. youtube.com/watch?v=JepKVUym9Fg (accessed August 25, 2018). surrounding these human-computer interactions, but Cooper 
3 Cooper, The Inmates Are Running the Asylum, 14-15.

4 Pieter Desmet and Paul Hekkert, "Framework of Product Experience," International Journal of Design 1, no. 1 (2007): 57-66; Marc Hassenzahl, Experience Design: Technology for All the Right Reasons, Synthesis Lectures on Human-Centered Informatics (San Rafael, CA: Morgan and Claypool, 2010); Mike Kuniavsky, "User Experience and $\mathrm{HCl}$," in The Human-Computer Interaction Handbook: Fundamentals, Evolving Technologies, and Emerging Applications (New York, NY: Lawrence Erlbaum Associates, Inc., 2007), 897-915.

5 IxDA, "About \& History - Interaction Design Association—-IxDA," https:// ixda.org/ixda-global/about-history/ (accessed October 25, 2017).

6 Tim Brown, Change by Design: How Design Thinking Transforms Organizations and Inspires Innovation (New York, NY: HarperCollins Publishers, 2009), 5.

7 Erik Bohemia, "Designer as Integrator: Reality or Rhetoric?," The Design Journal 5, no. 2 (2002): 23-34.

8 Brown, Change by Design; Jeanne Liedtka and Tim Ogilvie, Designing for Growth: A Design Thinking Tool Kit for Managers (New York, NY: Columbia University Press, 2011); Roger L. Martin, The Design of Business: Why Design Thinking Is the Next Competitive Advantage (Boston, MA: Harvard Business Press, 2009).

9 Richard J. Boland, Fred Collopy, Kalle Lyytinen, and Young Yoo, "Managing as Designing: Lessons for Organization Leaders from the Design Practice of Frank 0. Gehry," Design Issues 24, no. 1 (Winter 2008): 10-25.

10 Claudia Mareis, "The Epistemology of the Unspoken: On the Concept of Tacit Knowledge in Contemporary Design Research," Design Issues 28, no. 2 (Spring 2012): 61-71; Claudia Mareis, Design als Wissenskultur: Interferenzen zwischen Design- und Wissensdiskursen seit 1960 [Design as a Knowledge Culture: Interferences Between Design and Knowledge Discourses Since 1960] (Bielefeld: transcript, 2011) argues that the solutions to these problems do not begin with better technology:

As engineers, their belief is in technology, and they have faith that only some new technology, such as voice recognition or artificial intelligence will improve the user's experience. Ironically, the thing that will likely make the least improvement in the ease of use of software-based products is new technology. There is little difference technically between a complicated, confusing program and a simple, fun, and powerful product. The problem is one of culture, training, and attitude of the people who make them, more than it is one of the chips and programming languages. We are deficient in our development process, not in our development tools. ${ }^{3}$

Cooper implies that the solution to such fundamental problems is to find better production processes, dispel the faith of technologists in technology, and change the culture, training, and attitude of the people involved in the production processes. This can be understood as part of a larger movement of user-centered design, which has established a human-centered framework to guide design processes and shape human experience, rather than only physical interfaces. ${ }^{4}$ The IxDA (Interaction Design Association) worries that the "human condition is increasingly challenged by poor experiences. ${ }^{\prime 5}$ Design is stepping up to take on a central role in mediating innovation methods whereby the "power of design" is to perceive it as "the hub of a wheel." Erik Bohemia's research suggests that the role of integrator may reflect rhetoric generated from within design literature rather than organizational reality. However, as an integrator, design has attracted the attention of business management. ${ }^{8}$ For example, some management scholars were fascinated by the collaboration with architect Frank Gehry and his team, who illustrated how management might learn from design as a "mode of cognition and as an organizational practice." ${ }^{\prime 9}$

Design has been represented as an epistemology of tacit knowledge, and in a wider sense as a new and independent knowledge practice, materializing in practical methods such as design thinking. ${ }^{10}$ Design has also been represented as caring for the human experience. This makes the case for design as a human-centered methodology, where designerly ways of knowing are offered as the way to navigate innovation in a way that works for society. However, at the bottom of this is the assumption about a certain 
11 Donald A. Schön, The Reflective Practitioner: How Professionals Think in Action (New York, NY: Basic Books, 1983).

12 Herbert A. Simon, The Sciences of the Artificial, 3rd ed. (London, ENG: MIT Press, 1996), 112.

13 Schön, The Reflective Practitioner, 41.

14 J. Christopher Jones, "A Method of Systematic Design," in Conference on Design Methods, ed. Nigel Cross (Oxford: Pergamon Press, 1963), 11.

15 Jake Knapp, John Zeratsky, and Braden Kowitz, Sprint: How to Solve Big Problems and Test New Ideas in Just Five Days (New York, NY: Simon and Schuster, 2016). Other processes selected are User-centered design: BSI, “Ergonomics of Human-System Interaction-Part 210: Human-Centred Design for Interactive Systems" (ISO 9241-210:2010) (London: Standards Policy and Strategy Committee, 2010); User experience (UX) design: UXPA, "About UX | User Experience Professionals Association," https:// uxpa.org/resources/about-ux (accessed April 23, 2018); Design thinking: Martin, The Design of Business; Brown, Change by Design; Lean startup and Lean UX: Eric Ries, The Lean Startup (London: Portfolio Penguin, 2011), 75-77; Jeff Gothelf and Josh Seiden, Lean UX: Applying Lean Principles to Improve User Experience (Sebastopol, CA: O'Reilly Media, Inc., 2013); Value proposition design: Alexander Osterwalder, Yves Pigneur, Gregory Bernarda, and Alan Smith, Value Proposition Design: How to Create Products and Services Customers Want (Hoboken, NJ: Wiley, 2014), 94. nature of design. We explore these naturalizations in design theorizing in the following text. First we investigate the separations between theory and practice, which become visible in representations of the design process. Then we trace the differentiation of the human and the supposedly passive material in design activity. In the third section, we highlight the separation between subjective and objective knowing in design, as well as the absence of a concept of how subjective experience meshes with the socalled objective world. Finally, we question the proposition that designerly knowing is somehow an internal process, hidden from view. We conclude with a proposal to view design as an object that is made up in practice, rather than taking for granted this nature of design.

\section{Theoretical and Practical Knowing}

In regard to professional knowledge, the predominant logic has been a distinction and a hierarchy between theory and practice. ${ }^{11}$ Using this distinction, design has tended to lose out in a comparison with the natural sciences and is seen as "intellectually soft, intuitive, informal, and cookbooky." ${ }^{\prime 2}$ Applied work is seen to rely on theorizing from the sciences. Practical work, like design, was expected to use "professional knowledge as the application of scientific theory and technique." ${ }^{13}$ According to Donald Schön, the issue is that professional knowledge is understood to be the result of scientific theorizing, whereas the practice does not produce any knowledge but only applies knowledge acquired earlier. Universities and our education system work on this understanding. Theory and practice are seen as two different activities in which knowledge is produced in one and then brought to use in the other. The supposedly more difficult work, and higher regarded work, is the theoretical work.

In the discussion, there has been a historically textured systematizing of design activity, of which a famous example is the design methods movement and its postulated stages of design as "1. Analysis; 2. Synthesis; 3. Evaluation." ${ }^{14}$ Design activities are so separated into distinct stages. In Table 1, we identify seven design process models and provide brief descriptions of the processes. Some models, such as design methodology are older and go back to the 1960s, and some, like design sprint, are more recent. ${ }^{15} \mathrm{We}$ propose that there are similarities across these approaches whereby theoretical and practical knowledge are understood as distinct and separable elements in the process of designing and that this ongoing splitting of the world into theory and practice produces material effects. 
Table 1 | Selected Design Process Models

\begin{tabular}{l|l}
\hline $\begin{array}{l}\text { Design Process Model } \\
\text { Design methodology }\end{array}$ & $\begin{array}{l}\text { Description } \\
\text { Design methodology composed of analysis, synthesis, and evaluation; proposed to bridge the gap } \\
\text { between "logical analysis" and "creative thought" }\end{array}$ \\
\hline User-centered design (UCD) & $\begin{array}{l}\text { Defined in an international standard, describes the design process as a cycling through understanding } \\
\text { and production activities-"understanding and specifying the context of use," "specifying the user } \\
\text { requirements," "producing design solutions," and "evaluating the design" }\end{array}$ \\
\hline User experience (UX) design & $\begin{array}{l}\text { A more specific application of the user-centered design methodology; activities are described as } \\
\text { "Analysis," "Design," "Implementation," and "Deployment" }\end{array}$ \\
\hline Design thinking & $\begin{array}{l}\text { A reconciliation of the "two modes of thought": "analytical thinking" and "intuitive thinking, the art of } \\
\text { knowing without reasoning" }\end{array}$ \\
\hline Lean startup and Lean UX & $\begin{array}{l}\text { Emerged from the Lean manufacturing movement; making and learning are wrapped up in cycles of testing } \\
\text { hypotheses in "build-measure-learn feedback loops" }\end{array}$ \\
\hline Value proposition & $\begin{array}{l}\text { Adopts the Lean startup "build-measure-learn," and the design innovation triad technology-customer-business } \\
\text { value }\end{array}$ \\
\hline Design sprint & $\begin{array}{l}\text { A five-day process, an initiative from Google Ventures: Monday, "map out the problem"; Tuesday, "sketch } \\
\text { competing solutions"; Wednesday, "make difficult decisions and turn [...] ideas into a testable hypothesis"; } \\
\text { Thursday, "hammer out a realistic prototype"; Friday, "test it with real live humans." }\end{array}$
\end{tabular}

A recurring theme in Table 1 is the separation of theoretical activities (analysis, understanding, learning, logical thinking) and practical activities (synthesis, producing, implementation, building, intuitive thinking). As design processes, these activities should cover, on the one hand, understanding problems and, on the other hand, making solutions. However, practice studies of architectural designing have revealed no distinct steps of analysis and synthesis, but activities that are made up of both ways of knowing at the same time. ${ }^{16}$ The current representations of knowledge production in design represent nothing more than the conventional separations between thinking and doing, ignoring opportunities to perceive "embodiment and being in the world [as the] condition of knowing and action." ${ }^{17}$ Furthermore, the separation between "intellect" and "corporeal" creates a hierarchy between the objectified body directed by the mind. ${ }^{18}$ In summary, although each of these design process models attempt to provide new approaches to designing, they rest on very conventional

16 Henrik Gedenryd, "How Designers Work-Making Sense of Authentic Cognitive Activities" (PhD diss., University of Lund, 1998).

17 Lucy Kimbell, "Rethinking Design Thinking: Part I," Design and Culture 3, no. 3 (2011): 298.

18 Sarah Pink, Doing Sensory Ethnography (Thousand Oaks, CA: SAGE, 2009).

19 James J. Gibson, The Ecological Approach to Visual Perception: Classic Edition (New York, NY: Psychology Press, 2015); Klaus Krippendorff, “On the Essential Contexts of Artifacts," Design Issues 5, no. 2 (Spring 1989): 9-39; Donald Norman, The Design of Everyday Things: Revised and Expanded Edition (New York, NY: Basic Books, 2013). understandings of a theory-practice binary and work to reinforce that binary.

\section{The Human and the Material}

James Gibson's affordances are an important concept in theorizing the relationship between human and technology, which was also taken up by writers such as Klaus Krippendorff and Donald Norman, in the sense of "what one can do" with technology. ${ }^{19}$ If a terrestrial surface is nearly horizontal (instead of slanted), nearly flat (instead of convex or concave), and sufficiently extended (relative to the size of the animal) and if its substance is rigid (relative to the weight of the animal), then the surface affords support. It is a surface 
of support, and we call it a substratum, ground, or floor. It is stand-on-able, permitting an upright posture for quadrupeds and bipeds. It is therefore walk-on-able and run-over-able. It is not sink-into-able like a surface of water or a swamp, that is, not for heavy terrestrial animals..$^{20}$

Gibson describes the relationship between humans and the material surroundings as immediate, ${ }^{21}$ whereas Norman sees the material as subject to human cognitive interpretation: "the brain had to process the information arriving at the sense organs to put together a coherent interpretation." ${ }^{22}$ Gui Bonsiepe describes the interface as a connection between "a body," "a purposeful action," and "an artifact," also implying dependence on a purpose or intention..$^{23}$ The separation between cognition and body, human and technology, represents the cognition as active and the body and the material as passive matter. A hierarchy emerges between the human and the material. However, action (or the capacity to act) can alternatively be seen as distributed across humans and the material in more collaborative ways than are represented here. ${ }^{24}$ There has been considerable work done revealing the active participation of the material in action, illustrating how the material redistributes skills between humans and materials, conventionally ascribed to humans only. The material could be seen as actively shaping everyday human practices and experience. A study on DIY projects demonstrates the reconfiguration of "the distribution of skill" between the human and novel materials, such as "smart paints," which are "fast-drying, non-drip, water-based paints that 'know' how to go on to a door."'25 Elizabeth Shove and Mika Pantzar's study traces the coevolution of the material and meaning of "walking sticks" in the practice of Nordic walking. ${ }^{26}$ Tom Fisher studied plastic products and their affective significance to the practices of their owners. ${ }^{27}$ The way "things" seamlessly fit into and carry the social practices of their owners is demonstrated by Daniel Miller's work. ${ }^{28}$ Daniela Rosner illustrated how different kinds of material collaborations form activity on the basis of a bookbinding workshop. ${ }^{29}$ Material-material, material-human, and material-workspace collaborations produce the "emergent patterns" of work practice in which we "recognize the formative techniques and practices that hold lasting personal and cultural value." ${ }^{\prime 30}$ Following these accounts, the human-machine interface may be understood as an ongoing formation of skills, practices, and collaborations between humans and materials. ${ }^{31}$

Material collaboration in everyday life can be extended to information and digital realms. Although the digital is treated as immaterial, it lives through "large-scale material infrastructures of electrical power, air conditioning, servers, cables, and buildings,"

\footnotetext{
Lucy Suchman, Human-Machine Reconfigurations: Plans and Situated Actions (New York, NY: Cambridge University Press, 2007).
} 
32 Paul Dourish, The Stuff of Bits: An Essay on the Materialities of Information (Cambridge, MA: MIT Press, 2017), 202.

33 Sarah Pink, Heather Horst, John Postill, Larissa Hjorth, Tania Lewis, and Jo Tacchi, Digital Ethnography: Principles and Practice (London: SAGE, 2016), 68.

34 Wanda J. Orlikowski, "Sociomaterial Practices: Exploring Technology at Work," Organization Studies 28, no. 9 (2007): 1435-48.

35 Paolo Volonté, "The Thin Ideal and the Practice of Fashion," Journal of Consumer Culture (2017): 1-19. https:// doi.org/10.1177/1469540517717775.

36 Suchman, Human-Machine Reconfigurations; Orlikowski, "Sociomaterial Practices."

37 Suchman, Human-Machine Reconfigurations, 12.

38 Pink, Doing Sensory Ethnography.

39 Desmet and Hekkert, "Framework of Product Experience," 57-66; Kuniavsky, "User Experience and $\mathrm{HCl}$," 897-915; the increased attention on context in design is discussed by Kari Kuutti, "Artifacts, Activities, and Design Knowledge," in Design Integrations, eds. Sharon Poggenpohl and Keiichi Sato (Bristol: Intellect, 2009); Kari Kuutti and Liam J. Bannon, "The Turn to Practice in $\mathrm{HCl}$ : Towards a Research Agenda," in Proceedings of the SIGCHI Conference on Human Factors in Computing Systems (2014).

40 William Buxton, Sketching User Experiences: Getting the Design Right and the Right Design (San Francisco, CA: Morgan Kaufmann, 2007), 100.

41 Buxton, Sketching User Experiences, 10 and it actively participates in society through "constraints that bleed through to the human experience and to the social arrangements within which digital and virtual entities are embedded." ${ }^{\prime 32} \mathrm{Jo}$ Tacchi's research illustrates how "domestic soundscapes" help materialize memories of one's father shaving or create emotional balance for a person knowing "that there are other listeners to a late-night call-in show." ${ }^{33}$ Wanda Orlikowski demonstrates how Google search technology matters in different ways when researching historical events from different locations, such as from the United Kingdom or from China. ${ }^{34}$ Paolo Volonté analyzes how the "thin ideal" in fashion is constituted not just by models' bodies but also by the constraints of the formulas used to standardize measurements, which do not work beyond size 12 , thus materially enforcing size 12 as a barrier between "normal" and plus size. ${ }^{35}$

Contrary to the usual treatment of the material as passive and directed by intention, the human-material relationship may be reconceptualized as relations that produce particular effects. ${ }^{36}$ User-centered design does-as the name says-center the human as the dominant actor. Rather than viewing the human and the material as naturalized opposites, we may direct our gaze at how and to what effects the "boundaries between persons and machines [are] discursively and materially enacted." ${ }^{37}$

\section{Objective and Subjective Knowing}

Having discussed the separation of the human and the material, we consider another separation-that between subjective experience and objective knowledge. In the unfolding relationship between the human and the material, we have referred to the cognitivist understanding of human action, whereby experience and emotion is presented as the work of the brain interpreting bodily senses. ${ }^{38}$ With a rising focus on human experience and "context" as significant in human-material interaction, user-centered design has made efforts at theorizing how to design for subjective experience within the wider environment of interaction. ${ }^{39}$ The user's experience is conceptualized to be carried by their human body in interaction with a product (mountain bike) amid its material environment ("the mud, rocks, sticks, and yes, the water").40

[The] true outcome of the design [...] is not the physical entity or what is in the box (the material product) [...]. Rather, it is the behavioural, experiential, and emotional responses that come about as a result of its existence and its use in the real world. ${ }^{41}$

Personal experience is seen as subjective responses, which result from the interaction with the real and objective material. The world is seen as an objective set of conditions, and humans are 
42 Hassenzahl, Experience Design, 9-11.

43 Marc Hassenzahl, Sarah Diefenbach, and Anja Göritz, "Needs, Affect, and Interactive Products-Facets of User Experience," Interacting with Computers 22, no. 5 (2010): 354

44 Hassenzahl, Experience Design, 11.

45 Jon Kolko, "Abductive Thinking and Sensemaking: The Drivers of Design Synthesis," Design Issues 26, no. 1 (Winter 2010): 26, 15

46 Richard Coyne and Adrian Snodgrass, "Is Designing Mysterious? Challenging the Dual Knowledge Thesis," Design Studies 12, no. 3 (1991): 124-31.

47 Kerry Harman, "A Tentative Return to Experience in Researching Learning at Work," Studies in Continuing Education 40, no. 1 (2018): 17-29.

48 Leah Buley, The User Experience Team of One: A Research and Design Survival Guide (New York, NY: Rosenfeld Media, 2013), xvi.

49 IxDA, "About \& History."

50 Kolko, "Abductive Thinking and Sensemaking," 15; Bryan Lawson and Kees Dorst, Design Expertise (0xford: Architectural Press, 2009).

51 Brown talks about design being the "hub of a wheel": Brown, Change by Design, 5.

52 Brown, Change by Design, 69 conceptualized as subjective. Marc Hassenzahl outlines "objective conditions" to be elements such as time or the buttons on a device, while the "subjective experience" relates to concepts such as beauty or satisfaction. ${ }^{42}$ Among scholars there is a theoretical interest in solving the dynamic of unfolding interaction, which involves these supposedly objective materials and subjective experiences. For example, there is an attempt to sketch experience as the grade of fulfillment of "psychological needs," such as "autonomy, competence, and relatedness. ${ }^{\prime \prime 3}$ However, despite these detailed accounts of describing the role of experience in human-material interaction, user-centered design theorists admit there is much to unearth about the "transformation rules" that turn objective conditions into a subjective experience. ${ }^{4}$

Turning the gaze toward the designer's own body, experience, knowledge, and context, we can observe the same conceptual separations. Jon Kolko describes designerly sensemaking as synthesizing the designer's objective knowledge ("I saw this") with their subjective knowledge ("I know this"), which unfolds hidden "in the head." ${ }^{45}$ This is consistent with "romantic" explanations of design understood to be reliant on the designer's subjectivity, making designerly knowing "mysterious" and hidden from view. ${ }^{46}$ In addition to the separation between theory and practice highlighted previously, we see here a separation between objective conditions and subjective experience as two distinctly different kinds of knowing, which is taken as natural. Furthermore, "naturally" distinguishing objective conditions as out there in the world and subjective experience as hidden inside the human body obscures parts of the processes of knowing as hidden from view. ${ }^{47}$

\section{The Designer and the Nondesigner}

Designers want to be the "force for good" fighting for "technology [integrating] in our lives in a human way." "48 "We are driven by [the] belief that our practice of interaction design can make the world a better place [...] Interaction Designers strive to create meaningful relationships between people and the products and services that they use, from computers to mobile devices to appliances and beyond," says a professional association of interaction designers. ${ }^{49}$ But what makes designers able to do that? Design knowledge has accordingly been described as a cognitive style that takes place "in the head" of the designer. ${ }^{50}$ Designers are seen as connecting everything in a hub-theory and practice, human and material, and objective and subjective conditions. ${ }^{51}$ "[Their] creative process ... relies on synthesis, the collective act of putting the pieces together to create whole ideas." ${ }^{52}$ Design is presented as a skilled 
53 Nigel Cross, "Designerly Ways of Knowing," Design Studies 3, no. 4 (1982): 224.

54 Buxton, Sketching User Experiences, 114; Lawson and Dorst, Design Expertise, 104-12.

55 Cross, "Designerly Ways of Knowing," 224; Nigel Cross, "Designerly Ways of Knowing: Design Discipline Versus Design Science," Design Issues 17, no. 3 (Summer 2001): 49-55; Martin, The Design of Business, 5-6; Brown, Change by Design, 63-86.

56 Tom Fisher, "The Designer's SelfIdentity-Myths of Creativity and the Management of Teams," Creativity and Information Management 6, no. 1 (1997): 10-18.

57 Eric von Hippel, "Lead Users: A Source of Novel Product Concepts," Management Science 32, no. 7 (1986): 791-805; Jack Ingram, Elizabeth Shove, and Matthew Watson, "Products and Practices: Selected Concepts from Science and Technology Studies and from Social Theories of Consumption and Practice," Design Issues 23, no. 2 (Spring 2007).

58 Lucy Kimbell, "Rethinking Design Thinking: Part II," Design and Culture 4, no. 2 (2012): 129-48.

59 Fisher, "What We Touch, Touches Us," 20-31; Miller, The Comfort of Things; Rosner, "The Material Practices of Collaboration"; Shove, Watson, Hand, and Ingram, The Design of Everyday Life; Shove and Pantzar, "Consumers, Producers and Practices," 43-64.

60 Lucy Suchman, "Located Accountabilities in Technology Production," Scandinavian Journal of Information Systems 14, no. 2 (2002): 95. way of knowing that designers cannot "externalize." ${ }^{53}$ Design knowledge has sometimes been described as a mental cache that is expressable in drawing. ${ }^{54}$ In accounts of design thinking, design is represented as "tacit knowledge," "designerly ways of knowing," "forms of knowledge special to the awareness and ability of a designer," a reconciliation of the intuitive and the rational, and embracing the creative and the logical..$^{55}$

Two ideas are produced in these descriptions of designerly knowing. First, if we recall the separation between theoretical and practical knowing, the designer is understood to mediate and reconcile different types of knowledge with a wish to make technology more human. Second, designerly knowing is understood as internal and special to the designer, which also surfaced in the description of the subjective knowing of the designer. Conceptualized as an internal process, designerly knowing relies on the designer to be the medium of this knowledge, and the processing is hidden from view. In this narrative, design ability plays on the old notion of the designer "genius." ${ }^{56}$ Current design theorizing maintains the idea that design is something natural only to designers. This characterization ignores that designers are embedded in social and material environments in which collaborations of various kinds—human and material—take place. Design activity can hardly be demarcated as exclusive to the designer. For example, the user has been recognized as a source for "novel product concepts" in acquiring, scripting, appropriating, assembling, and normalizing products in everyday practice. ${ }^{57}$ When the production process is over, the design is not finished because the user "continues to be involved in constituting what a design is." ${ }^{15}$ We have also highlighted the material collaborations within which design work takes place. $^{59}$

But the conceptualizations of design activity do not tend to take into account these material and nondesigner contributions to design. Instead, they position the designers as the exclusive mediators of reconciling separate entities, such as theory and practice, subjective and objective knowing, and the human and technology. In this understanding, the designers "locate" these parts as "natural." Designers are thus conceptualized to be synthesizing "natural" locations. In this work, designers themselves remain locationless-they are rendered "unlocatable":

Within prevailing discourses anonymous and unlocatable designers, with a license afforded by their professional training, problematise the world in such a way as to make themselves indispensable to it and then discuss their obligation to intervene, in order to deliver technological solutions to equally decontextualized and consequently unlocatable users..$^{60}$ 
While designers remain without location, and thus unaccountable, they do locate and make accountable other forms of knowledge. This locating work amid imagining possible future realities is "profoundly political." ${ }^{61}$ Design work is currently undeclared and unchartered; as a methodology, it is exclusively accessible to designers.

There is much left to know about design as a way of innovating. The separation between theory and practice, as well as objective and subjective knowing, maintains the problematic tradition of knowledge binaries. The separation of the human and the material overestimates the agency humans have in what is happening, and it renders material agency invisible. Finally, the conceptualization of designerly knowing as natural and exclusive to the designer calls on the old myth of designer genius and produces the problematic effect of the unknown location of the designer within their own practices. Design as the methodology of innovation is an exclusive work. It is unlocatable, unaccountable, unchartered, and inaccessible to anyone outside of design practice. We call for a new conceptualization of design. To seriously investigate design as a way of knowing, we propose to move away from the narrative of design as a methodology of innovation and begin to look at the object of design and how it is made up.

\section{Conclusion: The Object of Design}

Taking categories as natural (such as human versus technology and designerly knowing versus conventional knowing) obscures the politics involved in making these categories. ${ }^{62}$ Design theorizing joins in with the creation of "ontological zones," naturalizing these different categories to continue synthesizing them again..$^{63}$ Design makes the case for making technology human; it emphasizes the importance of reconciling theoretical, practical, objective, and subjective knowing; it presents design knowledge as the natural ability of designers. Design thus describes the ontological makeup of the world. Rather than taking these ontologies for granted, we need to look at the effects of the work of assembling these categories. When design makes the case for design as a methodology, what does that do? Claudia Mareis speculates that tacit knowledge is less a natural state of design knowledge but a particular idea practiced and maintained by designers for reasons of independence. ${ }^{64}$ When design postulates that technology needs to be made more human through the "culture, training, and attitude of the people who make them," or when designers are reminded that it is "in your power" to change team and organization culture, these descriptions postulate particular ideas about design and produce particular effects. ${ }^{65}$ We have begun to explore these ideas

\footnotetext{
These quotes are from Cooper, The Inmates Are Running the Asylum, 14-15; and Buley, The User Experience Team of One, xvi.
} 
about design in the topics of theory/practice, human/material, objective/subjective, and designer/nondesigner. We argue that taking these categories as natural obscures the view on design activity and its effects, as well as the locations of designers. Design as a methodology of innovation is a particular idea about design work. As such, it is an object that is made up in practice, and as such, we propose to investigate it. 